\title{
THE PHILOSOPHY - TOOL CONTINUUM: PROVIDING STRUCTURE TO INDUSTRIAL ENGINEERING CONCEPTS
}

\author{
Mrs. L. van Dyk \\ Department of Industrial and Systems Engineering \\ School of Engineering \\ University of Pretoria \\ (Lvdyk@up.ac.za)
}

\begin{abstract}
Industrial Engineering concepts are often referred to as either a tool, technique, method, approach or philosophy. These terminologies can be positioned on a continuum according to their meaning as defined by the Oxford English dictionary (tools $\leftrightarrow$ techniques $\leftrightarrow$ methods $\leftrightarrow$ approaches $\leftrightarrow$ philosophies). The philosophy of Total Quality Management is used as example to show how the appropriate naming of Industrial Engineering concepts can enhance the understanding and application thereof. This continuum is used to show that although the philosophies of TQM and Scientific Management may differ, the same pool of tools and techniques are used by both of these philosophies.
\end{abstract}

\section{OPSOMMING}

Bedryfsingenieurs verwys dikwels na filosofieë, benaderings, matodes, tegnieke en gereedskap. Hierdie terminologieë kan kan op 'n kontinuum geposisioneer word na aanleiding van hulle woordeboekbetekenis (gereedskap $\leftrightarrow$ tegniek $\leftrightarrow$ metode $\leftrightarrow$ benadering $\leftrightarrow$ filosofie). Die filosofie van Totale Kwaliteitsbeheer (TQM) word as voorbeeld gebruik om te wys dat die gepaste benaming van Bedryfsingenieurskonsepte die begrip en toepassing daarvan verhoog. Hierdie kontinuum word gebruik om te wys dat, alhoewel die filosofie van TQM en Wetenskaplike Bestuur ("Scientific Management") verskil, dieselfde versameling van gereedskap en tegnieke deur beide gebruik word. 


\section{INTRODUCTION}

Many authors in the field of Industrial Engineering have brought our attention to the fact that the lingo of the Industrial Engineer is overpopulated with buzzwords and acronyms [1]. Terminologies, such as "tool(s)", "method(s)", "approach(es)" and "philosophies" are neither acronyms nor buzzwords. However, can you imagine a discussion or article in the field of Industrial Engineering, without any of these words?

The terminology "approach" appeared in six of the eight articles of the November 2000 issue of the South African Journal of Industrial Engineering, while "tool(s)" and "method(s)" were both present in four of the articles. Five authors made use of the word "technique(s)", while "philosophy(s)" appeared in two articles. "Method" and "Technique" were used as synonyms in two articles. In another article "approach" and "method" were used as synonyms, while "approach" was used within the same context as "technique" in yet another article.

Within this one issue of one journal the need to investigate the use of these terms are made evident. The Oxford Concise Dictionary are used as point of departure to determine a structure for the use of these terminologies.

\section{DEFINITION OF TERMINOLOGIES}

The Oxford Concise Dictionary [2] provides the following definitions for the terminologies under investigation:

Approach:

- A way of dealing with something.

Method:

- A particular procedure for accomplishing or approaching something.

Philosophy:

- A theory or attitude that guides one's behaviour. The study of the fundamental nature of knowledge, reality and existence.

Technique:

- A way of carrying out a particular task. A procedure that is effective in achieving an aim.

Tool:

- A device or implement, used to carry out a particular function. A thing used to help perform a job.

\subsection{Hierarchy of Terminologies}

In Figure 1 a hierarchy of terminologies is suggested, and explained thereafter. 
Figure 1: Hierarchy of terminologies

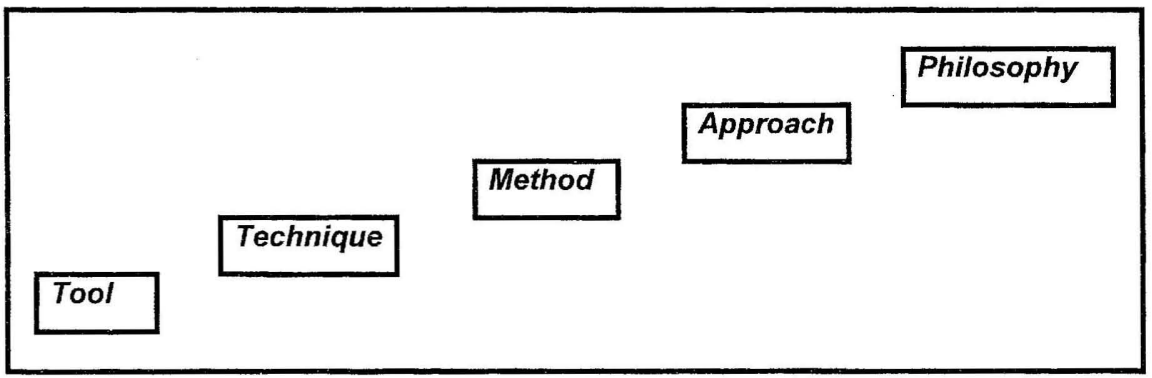

$\Rightarrow$ An approach is a way of dealing with the behaviour, guided by the philosophy.

$\Rightarrow$ A method is a specific procedure in the execution of an approach.

$\Rightarrow$ Both "technique" and "method" are defined as procedures. However, a technique is directed towards an aim, while a method is a procedure for approaching something. Therefore, method is positioned between "technique" and "approach".

$\Rightarrow$ "A single tool may be described as a device which has a clear role and defined application. It is often narrow in its focus and can be and is usually used on its own. A technique, on the other hand is normally a collection of tools." [3] A tool is used to carry out a specific function. A collection of these functions are performed as part of a the execution of a technique, which is a procedure that is effective in achieving an aim.

\subsection{Continuum of Terminologies}

It is suggested, furthermore, that the transition within this hierarchy occurs continually. Thus, the relationship between these terminologies can be positioned on a continuum, as shown in Figure 2.

Figure 2: Tool - Philosophy Continuum

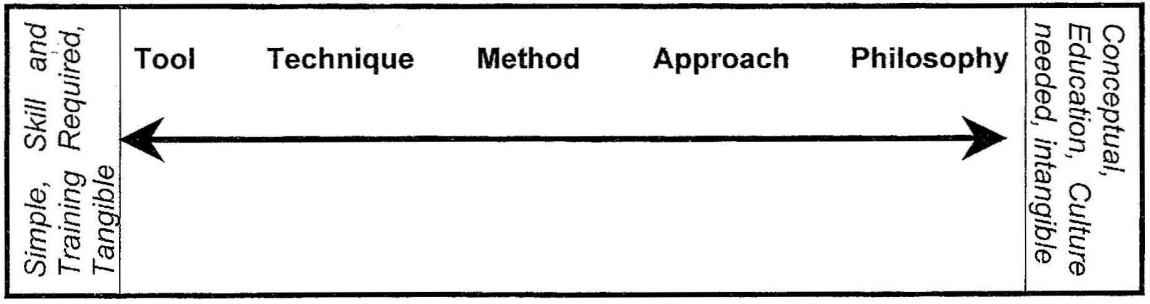


Philosophies appear at the right end of the continuum. The right end of the continuum represents conceptual, culture related concepts. As suggested by the Oxford definition, philosophies - on the right end of the continuum - guides behaviour. It is a way of thinking that influences the way of doing. One of Edward Deming's famous fourteen points is "Adopt the philosophy" [4]. For a philosophy to be adopted into an organization members need to be educated so that the philosophy can become part of the organisational culture. Philosophies are conceptual and related to national, industrial and corporate culture.

Whereas philosophies guide behaviour, an approach is less conceptual and more prescriptive, regarding the way of doing. A method and technique are even simpler than an approach and can be accomplished if the necessary skill level is present. For this reason mainly training is needed to obtain the skill to perform a technique, whilst education is needed to a greater extend to understand how to use an approach.

Tools appear on the left end of the continuum, since it is the most specific. A tool has a detail and practical application and skill to use a tool can be acquired through training only.

\section{THE PHILOSOPHY OF TOTAL QUALITY MANAGEMENT}

The philosophy of Total Quality Management (TQM) as well as approaches, techniques and tools within this philosophy are used as examples to explain the three parts of this continuum in further detail:
$\Rightarrow$ Approach - Philosophy Continuum
$\Rightarrow$ Method - Approach Continuum
$\Rightarrow$ Tool - Technique - Method Continuum

\subsection{Approach - Philosophy Continuum}

Examples of approaches within the philosophy of TQM are provided in Figure 3.

Figure 3: Approach - Philosophy Continuum (TQM)

\begin{tabular}{|c|c|c|c|c|c|c|}
\hline \multirow{2}{*}{ Tool } & Technique & Method & Approach & \multicolumn{2}{|l|}{ Philosophy } & 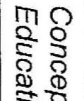 \\
\hline & \multicolumn{5}{|c|}{$\begin{array}{ll}\text { Deming's } 14 \text { points [4] } & \text { Total } \\
\text { Ishikawa's } & \text { Mana } \\
\text { Quality Circles [4] } & \\
\text { Taguchi's Quality Cost Function [4] } & \end{array}$} & 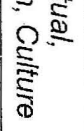 \\
\hline \multicolumn{4}{|c|}{ Plan-Do-Check-Act Cycle [7] } & ntinuous Improve & ment & \\
\hline
\end{tabular}


Slack [4] explains that TQM is best thought of as a philosophy of how to approach quality management as indicated on Figure 3. Continuous improvement is recognise as an approach towards TQM, but is also often regarded as a philosophy on its own. Hence, it is positioned near the philosophy-end of the continuum, but to the left of TQM.

The fact that the border between philosophies and approaches is unclear is probably one of the reasons why authors within the field of Quality Management are not consistent concerning the use of the terminologies, "philosophies" and "approaches":

Mitra [5] lists the following "Quality philosophies":

- Deming's 14 points for management;

- Philip B. Crosby's philosophy;

- Joseph M. Juran's philosophy.

Dale [6]- on the other hand - refer to the work of

- Crosby,

- Deming and

- Juran

as "approaches" towards Total Quality Management.

For purposes of this article, the above are categorised as approaches (Figure 3), since these are "a way of dealing with something", rather that a "theory or attitude that guides ones behaviour". The Plan-Do-Check-Act Cycle (Deming wheel) is positioned as a method, in Figure 3, since it is a procedure for accomplishing the approach of continuous improvement.

\subsection{Method - Approach Continuum}

Just-in-Time (JT) is closely linked to the TQM philosophy [4], and can be used as example to highlight the significance of the Method - Approach Continuum (Figure 4).

Figure 4: Method - Approach Continuum (TQM)

\begin{tabular}{|clll|}
\hline Tool Technique & Method & Approach & Philosophy \\
& & \\
& Kanban Method & JIT Approach & JIT-Philosophy \\
& ABC Method & & \\
\hline
\end{tabular}

JIT can refer to

- a philosophy (sometimes referred to as "big JT" [6]) or

- an approach (directing all activities towards the reduction of manufacturing wastes, such as time, defects, overproduction, over-processing, motion and transport, also called "little JT" [6]) 
Kanban is a method, a procedure for accomplishing the approach of reducing inventory levels. Similarly, the $A B C$ method (not be confused with activity based costing) is a method for analysing inventory based on value. Decisions regarding specific inventory management approaches are based on this method. Chase [7] categorises this method as an inventory planning method, alongside Kanban-type methods. The approach and philosophy associated with the $\mathrm{ABC}$ method are not discussed in this article. However, the example of the $A B C$ method will be pursued in further detail to discuss the Tool - Technique - Method Continuum

\subsection{Tool - Technique - Method Continuum}

The $\mathrm{ABC}$ method is a specific application of Pareto Analysis. Histograms and Cause-andEffect Analysis are building blocks of Pareto Analysis. The relationship between these, regarding the Tool - Technique - Method Continuum, is shown in Figure 5.

Figure 5: Tool - Technique - Method Continuum (Pareto Principle)

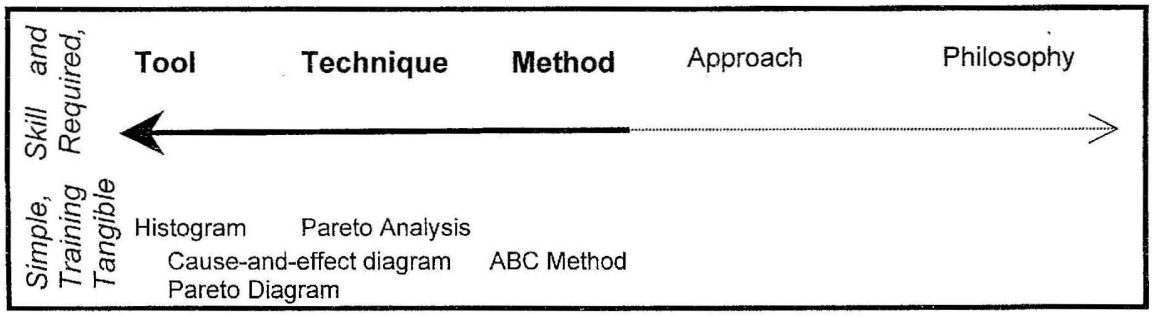

Histograms, flowcharts, check-sheets, pareto diagram/ analysis, flowcharts, cause-and-effect diagram and control charts are very often categorised together as "the seven quality tools/ techniques " [8][9]. Some of these tools/ techniques are positioned in Figure 5 on the Tool Technique - Method Continuum to guide the discussion that follows.

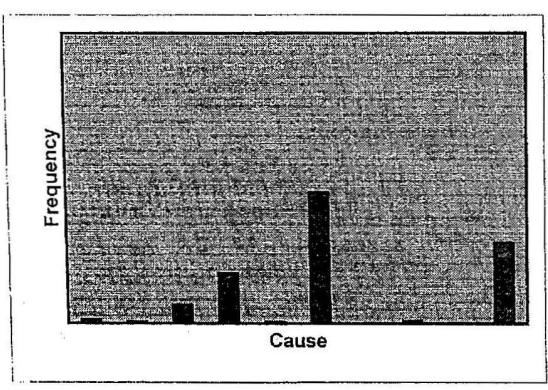

A histogram is a "bar chart showing data set divided into classes (bars) of equal width. Height of bar shows quantity. Shows patterns in dispersion of continuous data or large, discrete data sets." [8] 

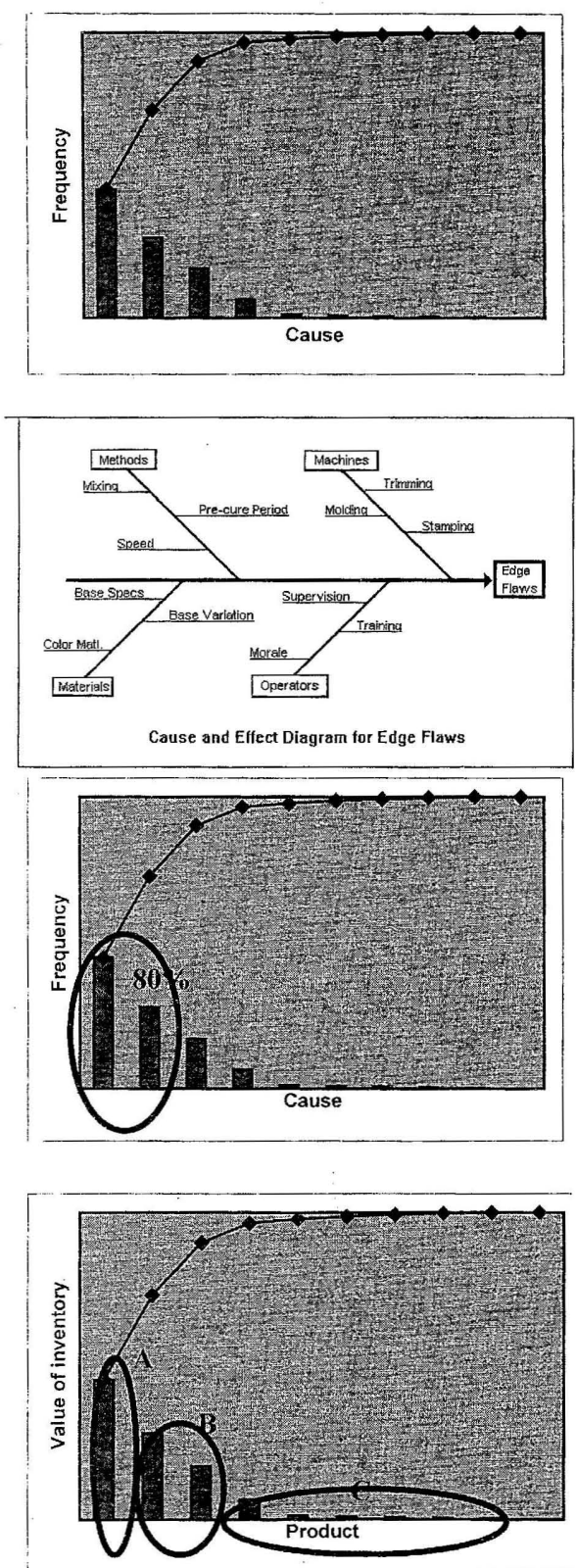

A Pareto Diagram makes use of the histogram and line chart tools to show graphically the relationship between causes and effects (or any other quantifiable category and related frequency).

"Experience shows that most problems can be largely accounted for by a small minority of the possible items or causes. A Pareto diagram is used to show this relationship. The data is categorised by items that are then arranged by magnitude. " [9]

The Cause - and -Effect Diagram is another way to show graphically the relationship between causes and effects. Therefore, the Cause - and - Effect Diagram share the same position of the Continuum (Figure 5) with the Pareto Diagram "Also called the Ishikawa Diagram, it is used to graphically portray the relation between a problem or situation (i.e. defect) and its many possible causes. "[9]

A Pareto Analysis appears more to the right of the Tool - Technique - Method Continuum in the sense that it builds upon the Pareto Diagram. Whereas the Pareto Diagram is only a graphical presentation, the Pareto Analysis requires further insight to identify the (approximately) $20 \%$ of causes that result in (approximately) $80 \%$ of the effects.

The ABC Method is categorised as a method, since it is a procedure that is used to approach the management of inventory. However, it is a manifestation of the Pareto Analysis. Products are divided into 3 categories $(A, B$ and $C)$ according to the total inventory value and are managed accordingly. 
In the same way methods, such as Single Minute Exchange of Dies (SMED), Statistical Process Control (SPC), Process Flow Charts, Quality Function Deployment (QFD) and Activity Sampling are build up out of a number of tools and techniques, as shown in Figure 6.

Figure 6: Tool - Technique - Method Continuum (Other examples)

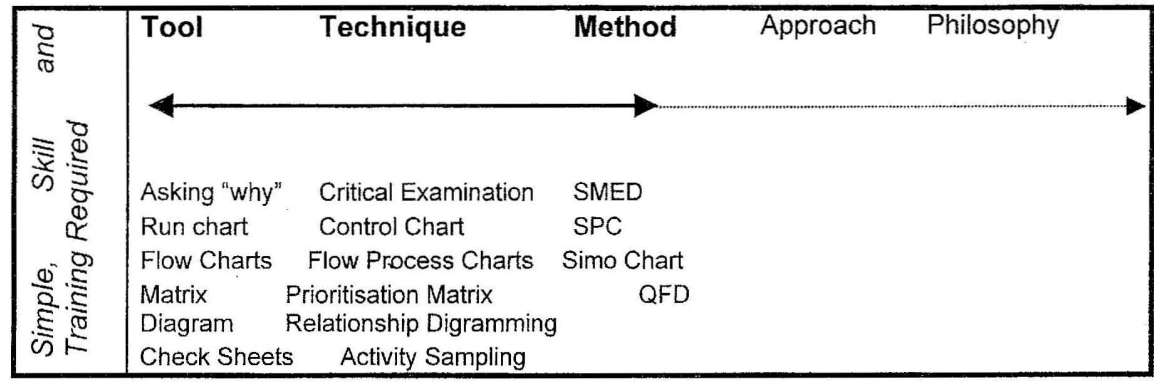

\section{TOTAL QUALITY MANAGEMENT vs. SCIENTIFIC MANAGEMENT}

Management approaches associated with F.W. Taylor's century old philosophy of Scientific Management are seldomly recognised in modern businesses. On the other hand, Total Quality Management approaches are used, or at least recognised, in the majority of businesses and industries. Whilst the philosophies of TQM and Scientific Management differ fundamentally, the same pool of tools, techniques and methods are shared, as shown in Figure 7 and explained thereafter.

Figure 7: Two different philosophies, one pool of tools, techniques and methods

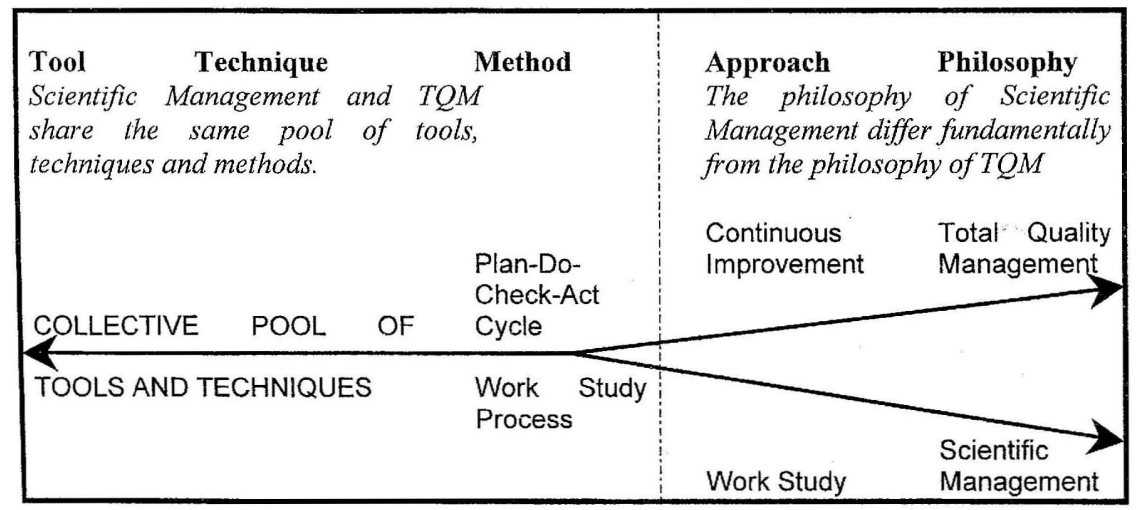




\subsection{Philosophies and approaches: TQM vs. Scientific Management}

Some differences between Continuous Improvement (an approach towards the philosophy of TQM) and Work Study (an approach within the philosophy of Scientific Management) are outlined below to support the right hand side of Figure 7.

$\Rightarrow$ An assumption of Work Study is that there is one best approach [10] while Continuous Improvement suggests that improvements must be sought continually and that the optimal solution will never be reached.

$\Rightarrow$ The Continuous Improvement approach prescribes small, but many, incremental changes, whilst improvements through Work Study can be either incremental or radical.

$\Rightarrow$ Work Study is traditionally being performed by a Work Study Officer [12], whilst employees are empowered and encouraged to run Continuous Improvement programs [7].

However, it can be shown that methods, techniques and tools that originated from Scientific Management, merges with methods, techniques and tools within TQM [13], as suggested by Figure 7.

\subsection{METHODS: Work Study vs. the Plan-Do-Check-Act Cycle}

The Plan-Do-Check-Act cycle (PDCA) is described by many authors as a method of accomplishing the approach of Continuous Improvement, within the philosophy of TQM [4][3][7][8]. To support the left hand side of Figure 7, the PDCA is compared with the Work Study Process in Table 1. In the first column, the steps of the PDCA cycle [7] are listed and described [12]. In the second column the corresponding Work Study step is described. If these two columns are compared it can be seen that these two methods are not identical. However, the resemblance is significant enough to support the suggestion in Figure 7 that the TQM continuum and the Scientific Management continuum are approaching each other, if methods associated with each philosophy are considered. ${ }^{1}$

A collective pool of tools and techniques appears in the third column of Table 1 . This list does not represent the full repertoire of tools and techniques available. However, it serves as example of the fact that more than one philosophy, approach or method draws upon the same pool of tools and techniques. It is suggested that there is no significant difference between the tools used by the philosophies of Total Quality Management and Scientific Management, as will be discussed in the subsequent section.

\footnotetext{
${ }^{1}$ The "Eight disciplines of problem solving" (8-D method) [14] is a procedure used in the Ford Motor Company within the philosophy of Total Quality Management. There is a great number of similarities between this method and each of the two methods outlined in Table 1. One of these similarities is the fact the same this method also makes use of the tools and techniques listed in the last column.
} 
Table 1: Comparison between the PDCA cycle and Method Study

\begin{tabular}{|l|}
\hline PDCA Cycle [7] \\
\hline $\begin{array}{l}\text { PLAN } \\
\text { - Delect Theme } \\
\text { - }\end{array}$ \\
Make clear why the theme is selected \\
Grasp the current situation \\
- Collect data \\
- Find the key characteristics of the \\
theme \\
- Narrow down the problem area
\end{tabular}

\section{PLAN}

\section{Conduct analysis}

- Establish priorities: serious problems first

- List all the possible causes of the most serious problem

Study the relations between possible causes and between causes and problem

- Select some causes and establish hypotheses about possible relations.

- Collect data and study cause-and-

\section{DO} effect relation

\section{Devise counter-measures}

- Devise countermeasures to eliminate the cause(s) of a problem

\section{DO}

\section{Implement counter-measures}

implement countermeasures (sometimes only on a experimental basis).

\section{CHECK}

Confirm the effect of counter-measures

Collect data on the effects of the countermeasures

Do before-after comparisons 


\subsection{TECHNIQUES AND TOOLS}

Kaoru Ishikawa introduced the following seven Quality Control tools (7QC tools) when he was head of the Japanese Union of Scientists and Engineers (JUSE) in the 1960's [7] [15]:

- Pareto Analysis

- Histogram

- Check sheets

- Cause - and Effect Diagram

- Scatter diagram

- Flow chart

- Control chart.

These tools and techniques are mainly directed towards quality control and are not the only tools and techniques that contributes towards TQM. For instance, during the 1970's a category of "new" quality control tools and techniques was defined [15]. This collection is also called the seven quality management tools and techniques. The seven "old" quality control tools and techniques, as listed above, are used as examples in the remainder of this article to show that Total Quality Management and Work Study share the same pool of tools and techniques.

\section{Pareto Analysis and Histogram}

Vilfredo Pareto in the $19^{\text {th }}$ century found that 20 percent of the people controlled 80 percent of the wealth. He defined the pareto principle accordingly. As explained earlier in this article [7], Pareto Analysis is a technique that draws upon tools such as histograms, as well as the pareto principle. Pareto Analysis was adopted by early Industrial Engineers and Work Study practitioners and is still being used [12]. Neither Scientific Management nor Total Quality Management has ownership over the Histogram tool or the Pareto Analysis technique, but the applicability of these within both philosophies and associated approaches is obvious.

\section{Check Sheets}

The exact origin of check sheets is unknown. However, it was used by mankind long before Ishikawa defined it as a Quality Control tool or Work Study practitioners used this tool as part of the Work Sampling technique.

\section{Cause and Effect Diagram and Scatter Diagrams}

The critical examination of all methods and tasks is embedded within Work Study [4]. The critical questioning technique [12] entails the answering of a number of systematic questions [12]: "What?, Why?, What could?, What should?" are asked with regard to all five dimensions of a job, namely purpose, person, place, sequence (time) and means. As with the Critical Examination technique, Cause-and-Effect diagrams and Scatter diagrams are aimed towards the identification of causes:

$\Rightarrow$ The Cause-and-Effect diagram prescribes an iterative cause finding process to determine the root causes. This technique are often chosen due to the simple and visual way in which the cause-effect relationship is shown. 
$\Rightarrow$ Quantifiable cause-and-effect relationships are identified by using Scatter diagrams,

$\Rightarrow$ The cause finding procedure of the Critical Examination technique is directed towards the identification of alternatives.

All three of these cause seeking techniques contributes to both TQM as well as Scientific Management:

$\Rightarrow$ The Cause and Effect diagram is a technique that was developed for purposes of TQM, but adopted by Work Study practitioners.

$\Rightarrow$ The Critical Examination technique was developed for Work Study, but adopted by Total Quality Managers [7].

$\Rightarrow$ Histograms originated neither from TQM nor Scientific Management. However, it was adopted by both philosophies.

\section{Flow chart}

As with check sheets and histograms, the technique of diagrammatically representing the flow of a process, did not originate from either TQM or Scientific Management, but it is recognised as a technique within both philosophies. The Process Flow chart conventions, as defined by the American Society of Mechanical Engineers [12] are strongly associated with the origins of Work Study, but it is also used as part of Total Quality Management.

\section{Other tools, techniques, approaches and philosophies}

The previous examples do not prove that all tools and techniques are applicable within all philosophies. The Control Chart is an example of a tool that is essential to the Total Quality Manager, but a work study practitioner may not find any value in using this tool. However, the Control Chart was adopted by other Industrial Engineering approaches and methods.

Most of the tools and techniques that was described or listed in the previous few pages are also used by other philosophies and approaches, such as Business Process Reengineering [7] and the Japanese 5 S's approach [15].

\section{CONCLUSION}

It was shown in this article that in the application of any philosophy (e.g. TQM), a number of approaches are used (e.g. continuous improvement of the reduction of inventory). One or more methods (e.g. the Kanban method) are used to follow an approach. Some methods (e.g. the $\mathrm{ABC}$ inventory method) are a specific application of a technique (e.g. Pareto Analysis), which in turn comprises of one or more tools (e.g. histograms). A tool - philosophy continuum was proposed accordingly. By means of the philosophy - tool continuum the conclusion was drawn that the philosophies of TQM and Scientific Management may differ, but the tools and techniques used by both are the same.

This philosophy - tool continuum can be used, furthermore, as model to compare philosophies, approaches, methods, techniques and tools that is currently used (as-is) with philosophies or tools that should be implemented (to-be). For example: Suppliers to Ford may be required to make use of Ford's 8-D (Eight Discipline) method. It will not be necessary to 
disregard the use of tools and techniques that are already in use (e.g. flow diagrams, questioning technique or pareto analysis). However, it may be necessary to adopt a teambased approach or the TQM philosophy, if this approach and philosophy are not already accepted. The positioning of the concept of the philosophy-tool continuum can serve as guideline in the implementation. Skills to use a tool are obtained through training, whilst a philosophy is adopted through education.

This article suggested a structured classification of Industrial Engineering concepts, which enhances the understanding and application thereof.

\section{REFERENCES}

[1] Koorts, CC., 2000. Implementation drivers for BPR at Siemens telecommunications, "Southern African Journal of Industrial Engineering", Vol 11, Nr. 1, p.53.

[2] The Concise Oxford dictionary of current English, 1999. Clarendon Press New York: Oxford University Press.

[3] Dale, B. 1998. - "Managing business improvement and quality : implementing key tools and techniques" - Oxford : Blackwell Business, p.22.

[4] Slack, N., Chambers, S., Harland, C., Harrison, A., Johnston, R., 1995. “Operations Management", Great Britain, Pearson Education Limited, pp.555, 576, 763-765.

[5] Mitra, A. 1993. Fundamentals of Quality Control, MacMillan Publishing Company, United States of America, 866 Third Avenue, New York, New York, 10022, p.36 - 62.

[6] Dale, B., Cooper, C.L., Wilkenson, A., 1997. "Managing Quality and Human Resources: A Guide to Continuous Improvement", Blackwell Publishers Ltd.; 108 Cowley Road, Oxford, OX4 1JF, United Kingdom, p.39-47.

[7] Chase, Richard B., Aquilano, Nicholas J., Jacobs, F. Robert., 1998. "Production and operations management : manufacturing and services", 8th ed., 0256225567, Boston : Irwin, pp. 216, 324, 337, 606, 607, 770-782.

[8] Mears, P., 1995. "Quality Improvement Tools and Techniques, McGraw-Hill, Inc, p. 16, p. 135.

[9] Akiba, M., Schvaneveldt, S.J., Enkawa, T.,1992. "Service Quality: Methodology and Japanese Perspectives", Handbook of Industrial Engineering ( $2^{\text {nd }}$ edition), John Wiley \& Sons, Canada, pp. 2349-2371.

[10] Nadler, G., The Role and Scope of Industrial Engineering, Handbook of Industrial Engineering (2 ${ }^{\text {nd }}$ edition $)$, John Wiley \& Sons, Canada, pp. 3-27, p.9, 1992. 
[11] Ho, Samuel K., 1995. "TQM : an integrated approach : implementing total quality through Japanese 5" - London : Kogan Page, -0749415614, p. 47.

[12] Kanawaty, G., 1992. "Introduction to Work Study", $4^{\text {th }}$ edition, International Labour Organisation, Geneva, ISBN 92-2-107108-1, p. 76.

[13] Brown, S., 1994. The Role of Work Study in TQM, "The TQM Magazine", Vol 06, Issue 3, ISSN 0954-478X.

[14] Lumsdaine, E., Lumsdaine, M., 1995. "Creative Problem Solving: Thinking skills for a changing world", McGraw-Hill International edition, General Engineering Series, p.17.

[15] Mizuni, S., 1998. "Management for Quality Improvement: The 7 New QC Tools", Productivity Press, Cambridge, p. vii. 